\title{
INDIOS EN CUBA COLONIAL: HOLGUÍNY JIGUANÍ, DOS CASOS DIVERGENTES
}

\section{Indians in Colonial Cuba: Holguín and Jiguaní, two divergent cases}

\section{Gerardo Licea Bello ${ }^{1}$}

Recibido: 15/6/2017 • Aprobado: 16/11/2017

DOI: http://dx.doi.org/10.22206/cys.2017.v42i4.pp41-51

\section{Resumen}

Entre finales del siglo Xviı y las primeras décadas del XVIII en la región bayamesa surgen dos nuevos asentamientos poblacionales: un "Pueblo de Indios" (Jiguaní), y un pueblo de "españoles" destinado a convertirse pronto en Ciudad (Holguín). A primera vista estas fundaciones tuvieron poco en común, y la evolución histórica de ambas localidades ha contribuido sin duda a alimentar esa certeza aparente: los holguineros se enorgullecen de su estirpe europea, con un mítico conquistador-fundador epónimo incluido, mientras en Jiguaní siempre se ha intentado preservar o "rescatar" la tradición indígena. Pero la consulta de las fuentes primarias conservadas evidencia que entre los habitantes del Holguín colonial había un número significativo de "indios", mientras que, por otro lado, el carácter de "verdaderos indios" de los habitantes de Jiguaní fue sistemáticamente negado por la oligarquía bayamesa a lo largo del siglo XVIII y defendido con igual vigor por las autoridades jiguaniceras. Para el caso holguinero se ha hablado de la "invisibilidad colonial del indio", pero ¿no podría hablarse también de una visibilidad motivada en el caso jiguanicero? El presente trabajo no pretende proporcionar respuestas, sino profundizar en la reflexión sobre el tema del "indio" en la sociedad colonial.

Palabras clave: indios; historia de Cuba; historia local; Holguín; historia colonial.

1. Profesor de Historia y Ciencias Sociales de la Universidad de Granma, Cuba.

E-mail: gerardolg@infomed.sld.cu

\section{Abstract}

Between the ending of the $17^{\text {th }}$ and the first decades of the $18^{\text {th }}$ century, it is worthwhile to note the appearance of two population settlements in the Bayamo region: a socalled "Indians town" (Jiguaní), and a "Spaniards" town, the latter of which was to evolve into a city-the city of Holguin-. At first glance, the two villages had little, if any, in common, and as a matter of fact, the historical evolution of both places has undoubtedly nurtured this too evident certainty: dwellers of Holguin nowadays are proud of their European ancestry-with a mythical conqueror-founder of the same name included-while in Jiguani, there have always been efforts to preserve or "rescue" the aboriginal heritage. However, consult of primary historical sources show evidence that there was a considerable number of indigenous inhabitants among the original dwellers of colonial Holguin, while, on the other side, the character of "true Indians" of Jiguanís population was systematically denied by the Bayamo oligarchy all throughout the $18^{\text {th }}$ century, at the same time that it was energically defended by the authorities of Jiguaní. In the case of Holguin, the phenomenon of the "colonial invisibility of the Indian" has frequently been discussed, but would not it be also possible to speak of a motivated visibility in the case of Jiguaní? This paper is not aimed at providing answers to this, but merely deepens on the reflections of the topic of the "Indian" in colonial society.

Keywords: indians; history of Cuba; local history; Holguín; colonial history. 


\section{Introducción}

Resulta complejo el estudio del "indio" en la sociedad colonial. Inferir su presencia a partir de evidencias arqueológicas en contextos coloniales puede constituir un error: "La identificación arqueológica del indio es complicada porque se trata de una identidad móvil, que quizás muchas veces no era asumida por gente a la que se le atribuía..." (Valcárcel Rojas, Hoogland y Hofman, 2014, p.23).

Los elementos de la cultura material indígena presentes en la sociedad colonial no eran exclusivos de los descendientes de aborígenes: a nadie se le ocurriría hoy considerar la existencia de una hamaca en un contexto contemporáneo -dígase, una unidad militar, o un campamento de pioneros exploradores- como evidencia de la existencia de una población aborigen en el lugar, y la misma cautela se debe aplicar cuando se trata de objetos utilitarios de tradición aborigen en contextos coloniales, que probablemente no hayan sido confeccionados ni utilizados por personas que se identificasen a sí mismos como indios.

A priori debemos aceptar que el indio es de por sí una construcción colonial:

El indio es el individuo que comienzan a crear los europeos... cuando la errónea idea de la llegada a Las Indias aporta una referencia para denominar poblaciones que se precisa conocer y sobre todo dominar. El indio es construido a medida que estas poblaciones son alejadas de su identidad precolombina y obligadas a vivir un ambiente colonial (Valcárcel Rojas y Pérez Concepción, 2014, p. 7).

El indio de los siglos XVI y XVII no es el indígena precolombino, sino el resultado de un proceso de transformación sociocultural profundo, está tan transculturado, mucho más, incluso, que el descendiente del conquistador español. Con este comparte su idioma, su religión, su modo de vida. A fin de cuentas, ¿qué es lo que lo diferencia radicalmente de los demás habitantes de la isla?: su historia, el hecho de ser descendiente de la población indígena precolombina. Es la legislación la que consagra esta diferencia fundamental, nos hallamos ante un caso de ius sanguinis: el indio colonial es ante todo una categoría jurídica basada en el origen étnico. Pero al mismo tiempo, el indio (y fundamentalmente "la india") toma parte activa en el proceso de mestizaje étnico que tiene lugar desde los inicios de la conquista. Un obispo de la Isla escribe en $1556^{2}$ : "los indios se van acabando y no se multiplican, porque los españoles y mestizos por falta de mujeres se casan con indias..." (Sarmiento, 2012, p. 61).

Pero el mestizaje del indio o de la india con el español no tenía necesariamente el mismo resultado final. El estatus socioeconómico del padre sin duda influyó mucho en el destino de los descendientes de aborígenes. En las primeras décadas coloniales se sabe que el mestizaje del conquistador y la india fue común. En algunos casos las circunstancias permitieron a estos mestizos heredar a su padre conquistador. En las raíces del árbol genealógico de más de una familia integrante de la oligarquía criolla es posible encontrar a una madre india. Pero esta situación, aceptable en los primeros tiempos de la colonización, pasadas algunas décadas dejó de ser común, y por lo mismo dejó de ser aceptada. El ámbito del indio se fue circunscribiendo cada vez más hasta quedar en una posición marginal y/o subalterna en la sociedad colonial.

\section{Identidad colonial del indio}

Es posible establecer varias etapas en la configuración de la identidad del indio colonial. En el transcurso de la segunda mitad del siglo xvi y primeras

2. Aunque generalmente se cita a Diego Sarmiento como autor de este documento, en 1556 el obispo de Cuba era Fernando de Uranga. 
décadas del siglo XviI se produjo un proceso evidente de transculturación -los testigos dirán espańolización- del indio, impulsado por el mestizaje y la convivencia con la población criolla de origen europeo y africano. Para confirmar esto basta comparar los testimonios aportados por los obispos de la Isla en diversos momentos de este proceso.

En 1544 el obispo Diego Sarmiento -testigo interesado- opinaba en contra de la libertad de los indios, pues consideraba que:

Como sean libres no harán sino holgar y hacer arreitos; con ellos perderán vidas y ánimos, y los vecinos sus haciendas y V. M la isla (...) puestos los indios en libertad, antes de dos años se despoblarán las villas del Puerto del Príncipe y Sanctispiritus, y la Trinidad, y la de Baracoa, y aun en el Bayamo creo quedarán pocos... Si todavía es servido V.M que los Yndios sean libres, si han de ser dotrinados, es menester un religioso en cada pueblo do tienen su asiento, porque si de alli los sacan, luego son perdidos y ahorcados o alzados ¿Y qué eclesiástico se hallará que quiera estar entre ellos?" (Sarmiento, 1973, p. 97-98).

Es decir que el indio encomendado aún conservaba importantes rasgos de su identidad pre-colonial, y se temía su retorno a su antiguo modo de vida si se le dejaba en libertad, abandonando los poblados y provocando la pérdida de la Isla, dicho de otro modo, aún no estaban realmente cristianizados ni "civilizados" del todo. Sin embargo, la implantación oficial unos pocos años más tarde de las Leyes Nuevas de Indias, y con ellas la eliminación de las encomiendas, desmintieron las apocalípticas previsiones del prelado, por el contrario, la desaparición de la encomienda al parecer aceleró el proceso de adaptación del antiguo indígena a la sociedad colonial, al encontrarse en una situación de relativa igualdad jurídica $-y$ de oportunidades- con el español.

En el contexto de muy baja presión demográfica que caracterizó a la Isla en la segunda mitad del siglo XVI y principios del siglo XVII, los indios, a pesar de su escaso número, constituían un componente demográfico importantísimo, y las posibilidades de mestizaje e integración con la escasa población de origen hispánico eran considerables, así no es de extrañar que los dos ocupantes sucesivos del obispado en el primer cuarto del siglo XvII hicieran énfasis en la espańolización de los indios y la mezcla de la población, dicho de otro modo, la integración del indio en la sociedad colonial criolla. Decía el obispo Juan de las Cabezas Altamirano en 1608: “...A los pueblos de indios que ay en esta tierra cassi no se les puede dar este nombre porque todos están españolados..." (Cabezas Altamirano, 2012, p. 96), mientras su sucesor, Alonso Enríquez de Armendáriz, planteaba en 1620:

...en toda esta isla no hay doctrina de indios (...) En esta dicha villa [Bayamo] había mil y quinientas almas, pocas más o menos, así de españoles como de indios, negros y mulatos, por que estando como están todos mezclados, no se pueden contar con más distinción que esta, y en este número no entran los que están en el campo (....) V. M. manda le avise como son tratados los indios que hay en los lugares de este obispado. Digo, que supuesto que no hay más indios en esta isla, que sean verdaderos indios, sino los pocos que he referido se hallan en cada pueblo mezclados ya con los espańoles. Estos son de la misma suerte tratados y enseñados como los demás españoles; y no tienen otros gravámenes o imposiciones temporales de consideración, solo en este pueblo de Guanabacoa, que es donde hay más número de indios, padecen muchísimo, porque les han usurpado sus tierras y los han arrinconado (Armendáriz, 2012, p. 140-147).

Resulta muy sintomático que los únicos indios que el obispo Armendáriz podía diferenciar del resto de la población eran los del pueblo de Guanabacoa, situado en las inmediaciones de La Habana, la única localidad de la Isla que por entonces vivía un 
intenso proceso de expansión demográfica y apropiación de la tierra. Mientras en el resto de la Isla españoles, negros, indios y mulatos se encontraban "todos mezclados", y resultaba "imposible contarlos con más distinción", en la región habanera se encontraban muy bien definidos quienes eran los indios, por tanto era posible concentrarlos en un punto geográfico bien determinado. Así, es en el momento de la expansión de la sociedad criolla, en la lucha por la ocupación de la tierra, que "la cuestión india" se convierte en un elemento importante, en un arma de doble filo que puede ser utilizada tanto a favor como en contra de aquellos que son identificados como indios. Veremos cómo en la Jurisdicción de Bayamo se evidencian ambas situaciones, pero con un siglo de retraso con respecto a la región habanera.

\section{Indios en Bayamo y Holguín}

En la primera mitad del siglo Xvir la presión demográfica sobre los amplios territorios de la Jurisdicción bayamesa era muy débil. Grandes extensiones de tierra permanecían prácticamente vírgenes, y ante esta sobreabundancia relativa de tierras los indios (al igual que los españoles, negros y mulatos "todos mezclados") tenían asegurado el acceso a las mismas. Es en esta etapa donde debe situarse la información aportada por el historiador bayamés Manuel José Estrada, al referir que, en una fecha no precisada, una Real Cédula ordenó al Cabildo de Bayamo reservar a los indios los terrenos de la parte norte de la Jurisdicción, o sea, lo que más tarde llegaría a ser la Jurisdicción de Holguín. En este hecho debe buscarse el origen del poblamiento de la región holguinera, y la explicación del significativo componente demográfico "indio" presente en el Holguín del siglo xviII.

Sin embargo, en el transcurso del siglo xviı se produjo un sostenido crecimiento demográfico, al que acompanó la consolidación de una expansiva oligarquía terrateniente que intentó acaparar la mayor cantidad de tierras posibles en la Jurisdicción. A mediados del siglo llegó a la villa una importante inmigración procedente de Jamaica, perdida para España en 1655. También arribaron en la segunda mitad del siglo algunas familias procedentes de Canarias. De los recién llegados algunos lograron integrarse con éxito a la oligarquía local en fase de consolidación, a la que aportaron algunos de los apellidos más representativos. ${ }^{3}$ Pero el incremento demográfico provocó necesariamente el desarrollo de contradicciones al interior del propio sector terrateniente criollo, no todos de cuyos representantes pudieron integrarse a la élite oligárquica, por lo que vieron obstaculizadas sus aspiraciones de ascenso social y económico.

Se produjo entonces una profunda estratificación de la población conducente a reforzar las diferencias sociales y circunscribir las posibilidades de acceso a la tierra y a los cargos públicos a una élite bien delimitada. Españoles, negros, indios y mulatos dejarán de estar "todos mezclados", como décadas antes, y aún dentro de la clase terrateniente se producirán diferenciaciones y exclusiones. En 1693 los regidores bayameses obtuvieron el derecho de reservarse para sí mismos uno de los cargos de alcalde ordinario, lo que dificultó aún el acceso a los cargos públicos-y a la tierra-incluso a algunas familias "de calidad".

Un revelador padrón de la población bayamesa fechado en 1684 separa cuidadosamente a los indios del resto de la población. Los indios empadronados se encontraban asentados "junto a la hermita de la señora Santa Ana y en el hato de Guanarubi y en Giguani arriba y en los quemados y en Cautillo y en el Sao" (AGI, Audiencia de Santo Domingo, Leg. 106, no. 79, año 1684, fol. 2v.). De estos lugares solo el Sao es un topónimo conocido de la

3. Sobre el origen de las familias bayamesas se debe consultar la obra genealógica de Prado (2012), escrita en el siglo XVIII. 
Figura 1. Mural que actualmente rememora hechos históricos importantes sobre la fudación del pueblo de San Isidoro de Holguín (foto de Jorge Ulloa Hung)

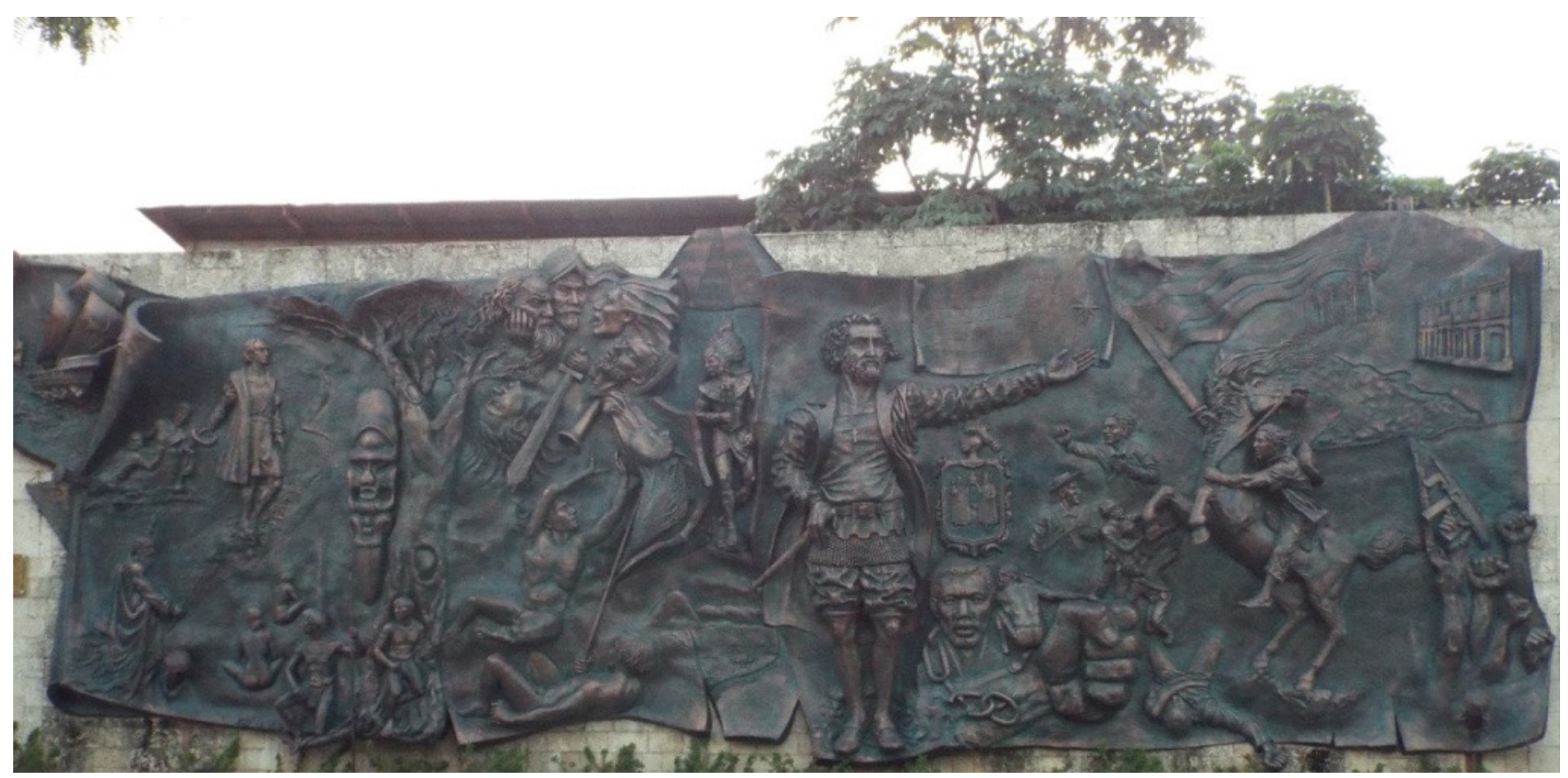

región de Holguín, y ni siquiera esta identificación es segura, el resto de los lugares citados se encontraban mucho más cerca de Bayamo. Resulta significativo que ya aparezcan Jiguaní Arriba y Cautillo como lugares habitado por indios, aunque según lo escrito por Manuel J. Estrada "sus terrenos no son los de la parte del Norte concedidos a los indios" (Estrada, 1840, p. 337). Por tanto, el derecho de posesión inicial sobre el corral de Jiguaní arriba no estaba basado en el origen étnico de sus poseedores.

En las últimas décadas del siglo XVII varias familias "blancas" iniciaron un proceso de apropiación de la tierra en el norte de la Jurisdicción ${ }^{4}$, en los territorios en otros tiempos reservados a los indios según Manuel J. Estrada. No conocemos ninguna evidencia documental de que se generara un enfrentamiento entre los antiguos y los nuevos poseedores, probablemente la cantidad de tierras fuera

4. Para la historia de la propiedad agraria en Holguín, véase Novoa (2008). suficiente, al menos durante algún tiempo para permitir la convivencia pacífica. Entre estas familias que sentaron las bases para la fundación de la futura Jurisdicción holguinera (los Ávila, González de Rivera, de la Peña, Hechavarría, de la Cruz, Leyva, de la Torre, Corral, Batista, Almaguer, etc.), algunas procedían de Jamaica, de Canarias o de Costa Firme. ${ }^{5}$ Otras habían radicado por generaciones en Bayamo, pero el denominador común era que se encontraban excluidas del Cabildo bayamés, por consiguiente no formaban parte de la oligarquía local, y resulta natural que buscasen la vía para emanciparse del control de esta. De ahí el motivo para fundar en 1720 el pueblo de San Isidoro de Holguín (figura 1), y las repetidas instancias para ser erigidos en Jurisdicción independiente, objetivo finalmente logrado en 1752 con la obtención del título de ciudad.

5. Sobre el origen de algunos de estos apellidos se puede consultar: Anónimo (s.f.) Libro de Familias holguineras, y Ávila (1926). 
Figura 2. Actual entrada del poblado de Jiguani (foto de Jorge Ulloa Hung).

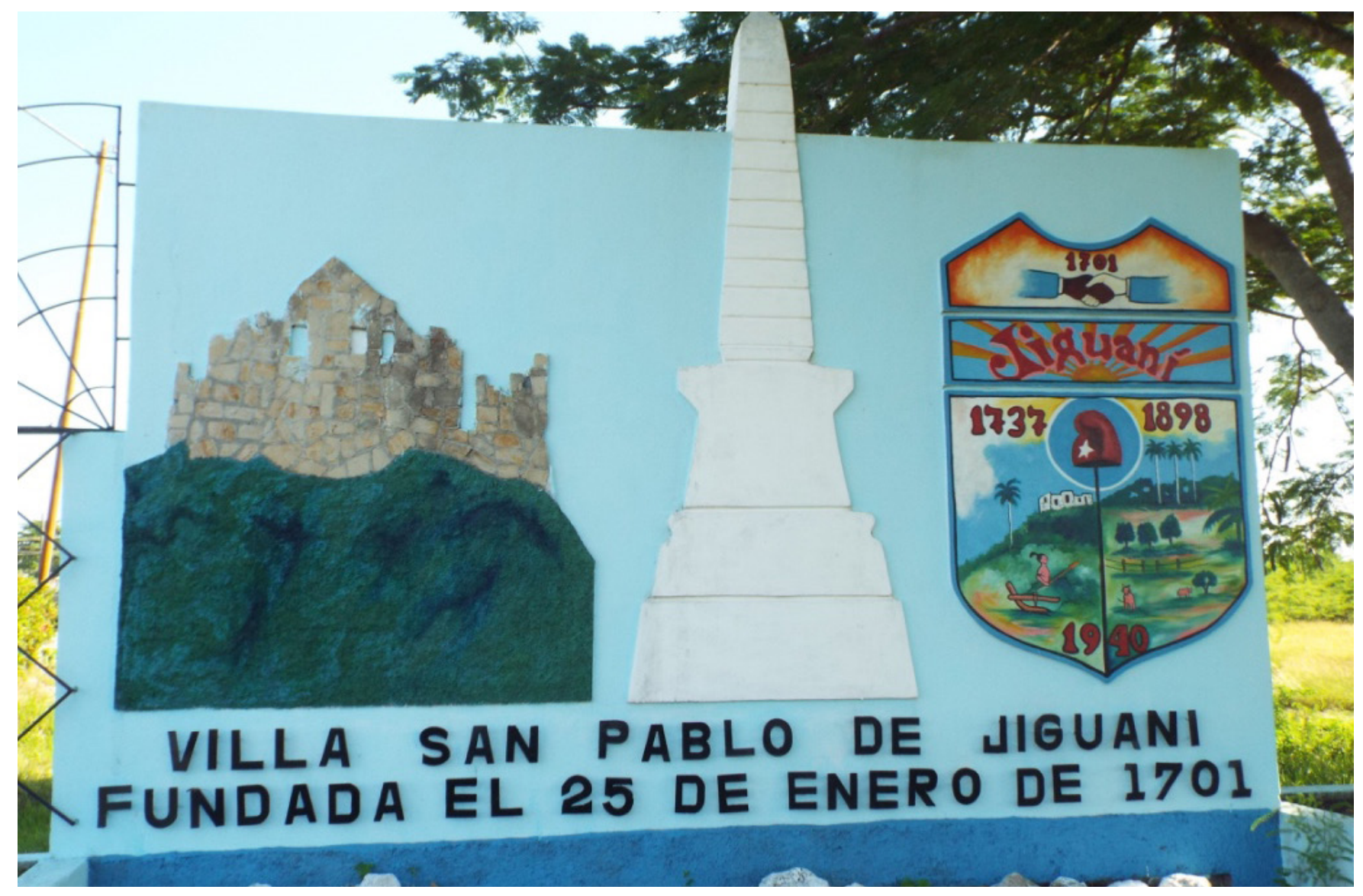

Aunque quizás entre los ascendientes de estas familias fundadoras del pueblo de San Isidoro de Holguín, hubiese alguna que otra abuela india, en ningún momento trascendió este dato. Indios sí habría en la nueva Jurisdicción, durante mucho tiempo, pero estos se encontraban en una posición social y económicamente subordinada, y en gran medida invisibilisados. A los fundadores de la flamante ciudad les convenía reafirmar su puro origen hispánico, primero tomando como punto de referencia a una matriarca de prodigiosa fecundidad, Doña María de las Nieves de Leyte Rodríguez de Aldana $^{6}$, y más tarde, retrotrayendo en el tiempo

6. Falleció en abril de 1741 a la edad de 130 años, según su partida de defunción (Libro $1^{\circ}$ de Defunciones de la Parroquia de San Isidoro de Holguín), aunque, siguiendo el análisis cronológico de Ávila (1926), tenía en realidad 103 años. el acto fundacional hasta un mítico conquistador epónimo, el capitán García Holguín.?

Mientras, en el resto de la Jurisdicción bayamesa el crecimiento demográfico condujo a pleitos inacabables por la posesión de la tierra, y en estos el tema indio terminó por aparecer, como mucho antes en la región habanera. Resulta evidente que en el proceso que condujo a la fundación del Pueblo de Indios de Jiguaní nadie pecó de ingenuo. Se trató de una estrategia bien calculada por parte de un grupo de personas interesadas en plantar a toda costa un valladar frente a la expansión de la oligarquía bayamesa. Seguramente el grupo fundacional, encabezado por Miguel Rodríguez, sí pertenecía a la comunidad de indios constatada

7. Para la discusión sobre este personaje, véase Novoa (2010). 
Figura 3. Casa de culata redonda y techo de cana asociada con la tradición indígena en Jiguaní (foto de Jorge Ulloa Hung).

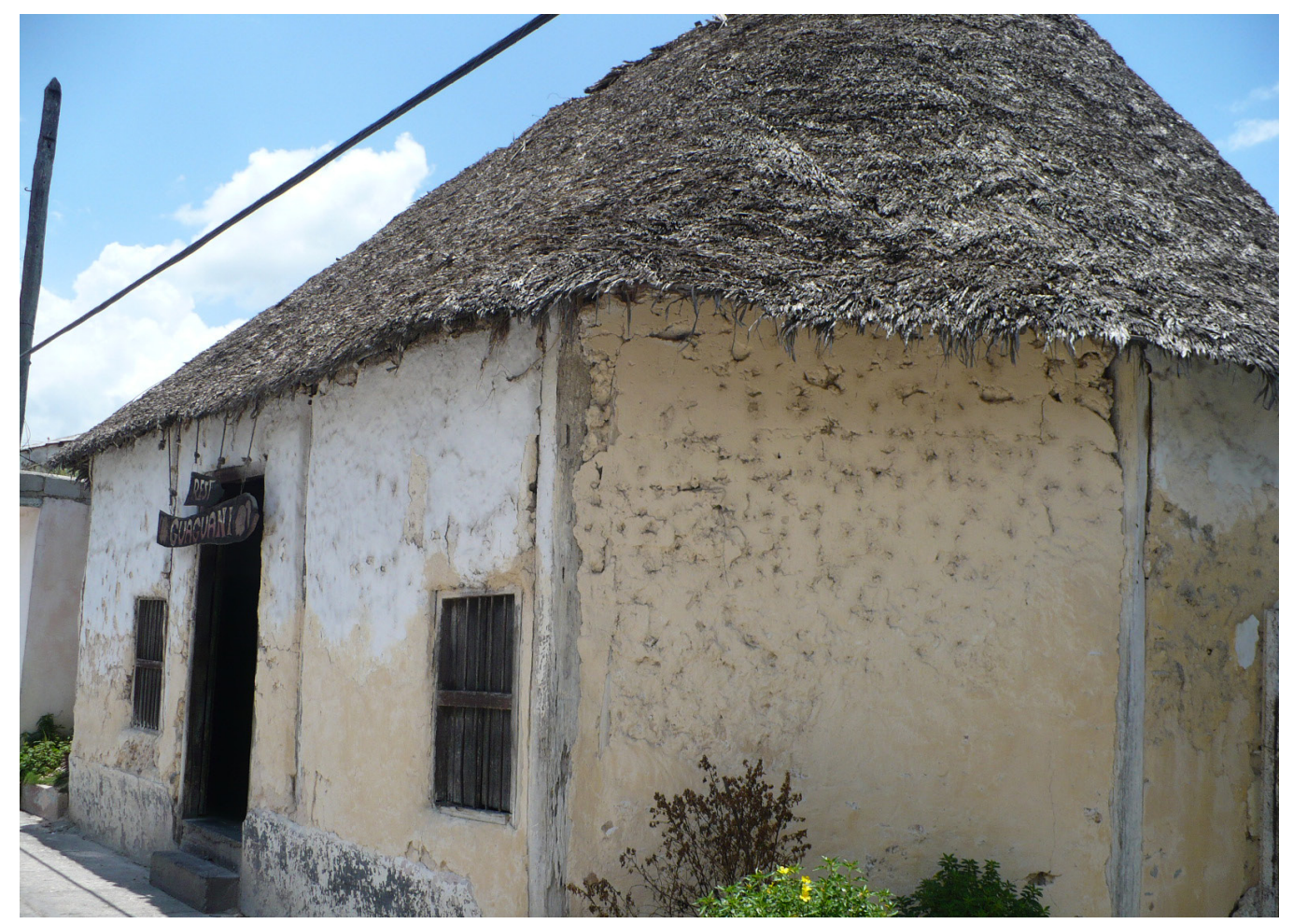

en el padrón ${ }^{8}$ de 1684 (que evidentemente debió estar muy transculturada y probablemente también mestizada), pero el éxito de sus gestiones para la constitución de un Pueblo de Indios tuvo varias consecuencias. Con la constitución del Pueblo de Jiguaní (figura 2) la oligarquía bayamesa se vio imposibilitada de extenderse a las tierras que le fueron reconocidas a los indios, pero al mismo tiempo los indios que habitaban fuera de la región de Jiguaní se vieron compelidos a marcharse hacia el territorio que les estaba destinado, abandonando por consiguiente cualquier derecho o reclamación sobre sus posesiones anteriores, aunque en definitiva muchos lograron quedarse en la villa, "especialmente aquellos que blasonaban de ser descendientes de los Casiques y de otros troncos

8. En ese documento aparecen 12 vecinos cabezas de familia con este apellido, además de varias mujeres y numerosos hijos mayores de 14 años, incluyendo dos Miguel Rodríguez. respetables, o que tenían hacienda en propiedad" (Estrada, 1840, p. 337).

La constitución del Pueblo de Jiguaní no solo benefició a los indios, sino que atrajo a un número considerable de personas que, a través de su enlace con familias "indias", tuvieron acceso a un estatus socioeconómico que les hubiera sido imposible obtener en Bayamo u otras "villas de españoles" (figura 3). Fue esta afluencia la que permitió consolidar la nueva población, pero al mismo tiempo provocó que desde muy pronto se pusiera en tela de juicio su estatus legal como Pueblo de Indios, pues rápidamente se convirtió en una población predominantemente mestiza, con algunas familias blancas sin mestizaje aparente, y muy pocos indios "puros". Esta situación ya era un hecho a mediados del siglo XVIII, cuando realizó su visita pastoral el obispo Morell de Santa Cruz en 1756:

Este pueblo era uno de los que havia en tiempo de los Yndios, y por tal se ha tenido después, 
aunque raro es el que ha quedado de Color de esta nación, porque á la reserva de una familia, que lo conserva, todas las demás son mestizas, y dos, ó tres blancas, que se han avecindado en él (Morell de Santa Cruz, 2005, p. 97).

En 1780 un grupo de representantes de la oligarquía bayamesa, afectado en sus intereses por la anulación de las mercedes concedidas por el Cabildo de Bayamo a orillas del río Cautillo declaraba:

... La población de Jiguaní y reducción de los Naturales, a que se acogen los que nos persiguen es un puro engaño con que tienen alucinadas las superioridades para merecer su protección, y es un caviloso artificio con que se han armado para acometer a nuestro fundado Derecho: Esa población señor no es de Indios Naturales como se denomina pues apenas se encuentra tal qual con las apariencias de su color (...) todos los que constituyen a dho Pueblo son Blancos y Mulatos que con el pretexto de gozar las indulgencias de los Naturales, han formado su congreso en aquel Pueblo (...) el Alférez Real actual Josef Rondón es blanco, natural de esta Villa como es notorio. El Rexidor Francisco de Mora, también blanco oriundo de esta Villa; el Rexidor y Alcalde actual Miguel del Toro es igualmente blanco cuyo padre Rosendo del Toro y su Muger vinieron de la Ciudad de Cuba (...) el Rexidor Miguel Rodríguez Balvoa es el único que tiene alguna tintura de Indio (...) Pero es casado con mujer blanca natural de esta Villa y su prole como reputada de la propia clase, ha casado ya una hija con un Irlandés; El rexidor Bruno de Fonseca que es el ege y motor de tantos disturbios, y continuas persecuciones que padecemos los vecinos del Bayamo (...) es este Señor un hombre blanco nativo de esta Villa Bayamo, donde permanecen sus hermanos y los demás individuos de su familia quienes lejos de estimarse por Indios, antes blasonan de ser descendientes de Europeos (...) El Capitán Don Antonio de Armas y Castillo otro vecino de dicho pueblo es natural de esta Villa criado y educado en ella y nieto lexitimo de $\mathrm{D}$. Melchor del Castillo difunto rexidor que fue de esta Villa. (...) Solo se titulan Indios naturales los habitantes de aquel Pueblo para inducir mańosamente la clemencia de nuestro soberano a que les imparta la merced de tierras Realengas para su uso perjudicando su Real Erario, con tener suspenso el beneficio y composición de ellas (Archivo Histórico Municipal de Jiguaní, Documentos transcritos por Enrique $\mathrm{O}$. Lacalle, AGI, Audiencia de Santo Domingo, Leg. 1619, año 1780).

En 1785 el gobernador de Santiago de Cuba, Nicolás de Arredondo informaba que los vecinos de Jiguaní

...corriendo hoy con el supuesto nombre de indios hacen por lo mismo ineficaces las providencias del gobierno de Cuba, porque apenas se procede contra algún vecino de Jiguaní, por los considerables excesos que a cada paso cometen...ocurren a la Real Audiencia de quien alcanzan de plano Provisiones en que se les manda poner en libertad, sobreseer y remitir las causas, quedando estas suspensas, libres los reos y más propagados los delitos (AGI, Audiencia de Sto. Domingo, Leg. 1617, año 1785, citado por Marrero, 1984, p. 129-131).

En ese año, la población del Jiguaní ascendía a 2569 en el pueblo y partido, de los cuales 428 eran cabeza de familia, cuya naturaleza se especificaba así:

Naturales nacidos y bautizados .175 en el pueblo

Hijos de madres nacidas y .4 bautizadas en el pueblo Casados con mujeres nacidas y bautizadas en el pueblo

No nacidos, ni hijos de madres del pueblo, ni casados con nacidas en el pueblo 
Arredondo informaba que no incluía

en esta enumeración las mujeres, hijos, agregados y sirvientes entre los cuales se cuentan más de 200 bayameses, muchos cubanos, varios del Reino de México, Europa, Canarias, Irlanda, Inglaterra, Cobre y Guinea, sin que en estas circunstancias pueda yo atinar ni distinguir la razón con que podrá llamarse de indios naturales un pueblo que sobre carecer de alguno que lo sea, en realidad se halla compuesto de tan diversas gentes que allí se han acogido con los fines de ejecutar otras usurpaciones perjudicialísimas al servicio de Dios, el Estado y la causa pública (Ibídem, p. 131).

\section{Conclusiones}

A manera de conclusiones podemos plantear que, mientras en Holguín, como en la mayor parte de la Isla, los indios constituyeron -junto a negros y mulatos- un sector subalterno, para el que se encontraban vedados los cargos concejiles y la posibilidad de ascenso social a través del matrimonio, el Pueblo de Indios de Jiguaní constituyó la otra cara de la moneda. Aquí el acceso a los cargos públicos estaba en principio, restringido a los "Indios naturales" y a los blancos mezclados con ellos. Si en Holguín y Bayamo el matrimonio con un cónyuge identificado como indio natural implicaba un descenso en la escala social, apenas menos denigrante que el matrimonio con un negro o mulato, en Jiguaní, por el contrario, constituía la fórmula para "naturalizarse" y poder disfrutar de los privilegios conferidos a los naturales ${ }^{9}$, de ahí la insistencia de los jiguaniceros, a lo largo de más de un siglo, en defender a toda costa su status legal de indios, más allá de la verdadera procedencia de algunos de sus antepasados, identidad india asumida y defendida conscientemente, en tanto llevaba implícita la

9. Consultar a Tamames Herdenson (2009). supervivencia de la comunidad frente al peligro de absorción por parte de la oligarquía bayamesa. En Holguín y Bayamo, donde la identidad de indio no aportaba privilegio alguno, y por tanto no había interés evidente en conservarla, "al fin el continuo trato y relaciones con los espańoles los convirtieron y reputaron por blancos" (Estrada, 1840, p. 337), sin que ello implique que no subsistieran familias o comunidades aisladas que conservasen durante largo tiempo una identidad india.

\section{Referencias}

Anónimo. (s.f.). Libro de Familias holguineras (manuscrito inédito). Holguín: Archivo Histórico Provincial de Holguín.

Armendáriz, A. E. (2012). Relación del obispo fray Alonso Enríquez de Armendáriz, 1620. En Portuondo Zúńiga, O. (Ed.). El Departamento Oriental en Documentos. Tomo I (1510-1799) (pp. 137-153). Santiago de Cuba: Editorial Oriente.

Ávila y Delmonte, D. (1926). Memorias del Hato de San Isidoro de Holguin. Holguín: Imprenta El Arte.

Cabezas Altamirano, J. (2012). El obispo fray Juan de las Cabezas Altamirano a su Majestad, 1608. En Portuondo Zúniga, O. (Ed.). El Departamento Oriental en Documentos. Tomo I (1510-1799) (pp. 95-101). Santiago de Cuba: Editorial Oriente.

Estrada, M. J. (1840). Estracto de Noticias sobre Bayamo. Memorias de la Sociedad Económica de Amigos del País, tomo x, p. 335-350.

García Castañeda, J. (2002). La municipalidad holguinera. Su creación y su desenvolvimiento hasta 1799. Holguín: Ediciones Holguín.

Lago Vieito, A. (1994). Los aborigenes de Bayamo. Destino y legado histórico. La Habana: Ciencias Sociales (Colección Pinos Nuevos). 
Marrero Artiles, L. (1984). Cuba. Economía y sociedad. Vol. 10: Azúcar, ilustración y conciencia (17631868) (II). Madrid: Playor.

Morell de Santa Cruz, P. A. (2005). Obras. La Habana: Imagen Contemporánea (Biblioteca de Clásicos Cubanos no. 36).

Novoa Betancourt, J. (2008). Haciendas ganaderas en Holguin, 1545-1867. Holguín: Ediciones Holguín.

Novoa Betancourt, J. (2010). García Holguín. Nueva Visión. Holguín: Ediciones Holguín.

Pérez Cruz, F. (Ed.) (2014). Los indoamericanos en Cuba. Estudios abiertos al presente. La Habana: Ciencias Sociales (Colección Alba Bicentenario).

Pichardo Moya, F. (1945). Los indios de Cuba en sus tiempos históricos. La Habana: Academia de la Historia de Cuba.

Pichardo Viñals, H. (2006). Temas históricos del Oriente cubano. La Habana: Ciencias Sociales.

Portuondo Zúńiga, O. (Ed.) (2012). El Departamento Oriental en Documentos. Tomo I (1510-1799). Santiago de Cuba: Editorial Oriente.

Prado y Pardo, P. (2012). Las Familias de Bayamo, 1512 - 1775. Bayamo: Ediciones Bayamo (Proyecto Memoria).

Sarmiento, D. (1973). Carta del Obispo al Emperador dando cuenta de la visita hecha a las villas e iglesias, y del estado en que se hallan, Santiago de Cuba, 25 de julio de 1544. En Pichardo Viñals, H. (Ed.). Documentos para la historia de Cuba, tomo I (pp. 96-101). La Habana: Ciencias Sociales.

Sarmiento, D. (2012). Copia de carta de Fr. Diego Sarmiento, obispo de Cuba, fecha en la villa de Bayamo a 20 de abril de 1556. En Portuondo Zúńiga, O. (Ed.). El Departamento Oriental en Documentos. Tomo I (1510-1799) (pp. 61-63). Santiago de Cuba: Editorial Oriente.
Tamames Henderson, M. (2009). El indio en el tejido social cubano. Estudio de casos. En Memorias del Crisol, tomo VII (pp. 84-129). Bayamo: Ediciones Bayamo.

Valcárcel, R., Hoogland, M., \& Hofman, C. L. (2014). Indios. Arqueología de una nueva identidad. En Valcárcel, R. \& Pérez Concepción, H. (Eds.) Indios en Holguin (pp. 20-42). Holguín: Editorial La Mezquita.

Valcárcel, R. \& Pérez Concepción, H. (2014). Introducción. En Valcárcel, R. \& Pérez Concepción, H. (Eds.) Indios en Holguin (pp. 7-13). Holguín: Editorial La Mezquita.

Valcárcel, R. (2016). Cuba. Indios después de Colón. En Ulloa Hung, J. \& Valcárcel, R. (Eds.) Indigenas e indios en el Caribe. Presencia, legado y estudio ((pp. 7-48). Santo Domingo: INTEC.

\section{Fuentes documentales}

Archivo General de Indias (1684). Padrón de vecinos de Bayamo de 1684 (Fondo Audiencia de Santo Domingo, Legajo 106, no. 79). Sevilla, España.

Archivo Histórico Municipal de Jiguaní (s.f.). Documentos del Archivo General de Indias transcritos por Enrique Orlando Lacalle (copias mecanografiadas): Audiencia de Sto. Domingo, Legajo 1619, año 1780. Jiguaní, Cuba.

\section{ANEXO 1}

"Por diciembre de 1707 Miguel de Aguilar, Sebastián Núnez y Matheo Ximénez, indios naturales residentes en el barrio y Parrochia de S. Juan Evangelista de la Villa de Bymo y Sta Ana de la susodha Villa por si y en nombre de los demás naturales vecinos de aquella Villa y citadas feligresias llevaron recurso de apelación de un auto provehido por D. Adrián Ricardo de Armandias, Alcalde Ordinario de dha Villa en que mandaba que dentro de cierto término y con penas pecuniarias 
aquellos naturales pasasen a hacer casas y población en el partido llamado de Jiguaní, y expusieron que siendo ellos como era de tiempo inmemorial feligreses de las enunciadas dos Parroquias extramuros de la Villa de Bayamo (...) Miguel Rodríguez a quien daban nombre de Teniente del Pueblo de Jiguani..., les incitaba a pleitos para que costeandole pudiese comparecer en los Tribunales Superiores a pretesto de que se les usurpaban sus tierras y otros semejantes catequizándolos con que les haria República por haber conseguido se erigiese Curato en el partido de Jiguani e induciendo a el Cura (...) a que les fomentase para conseguir que diferentes personas de todas calidades tanto de dha Villa como de fuera que les ofrecian tierras en que poder usar de las labranzas de tabaco que concurriendo con este pretexto muchas gentes pasarian a empadronarlos por vecinos y feligreses de dho Curato para que hallándose mucho numero (...) y con que se fabricasen 6 u 8 ranchos de paja en el paraje donde tenian una corta parroquia de lo mismo, podrían más comodamente quitar las tierras a los circunvecinos diciendo hallarse cortas las que poseían para tantas familias (...) por cuya razón el Rodriguez habia intentado con la Justicia del Bayamo suponiendo ser mandato de la R. Aud. que compeliese a los que asistian en dha Parrochia y Curatos de S. Juan y Sta Ana para que pasasen a residir en el partido de Jiguani (...) Prosiguieron representando el prejuicio que se le infería en perder sus casas y labranzas adquiridas con sus trabajos; que jamás habian sido feligreses del partido de Jiguaní, sino solo de S. Juan Evangelista y de Sta. Ana..." [Archivo Histórico Municipal de Jiguaní. Documentos del Archivo General de Indias transcritos por Enrique O. Lacalle, Legajo 1617 no. 3].

\section{ANEXO 2}

"Los vegueros que cultivaban tabaco en las tierras aluviales del hato de Vicana, en la jurisdicción de Bayamo, lograron una R. C. que les amparaba como indios naturales. D. Bartolomé de Aguilera, quien aseguraba ser su propietario, denunciaba en
1733 que con “....malicia han pretendido persuadir que son indios naturales...sin que ya pueda encontrarse [en Bayamo] indio natural, por su total exterminio, y porque los que únicamente se hallan están retirados en el pueblo de San Pablo de Jiguani, ... donde tienen asignados 14 leguas de latitud y más de 30 de longitud de territorio, para que en su distrito puedan libremente cultivarlas y labrarlas y se mantengan de su usufructo, sin que otra persona alguna tenga intervención ni interés en dichas tierras"

En apoyo de Aguilera declaró el capitán y regidor D. Diego de Berdecia que: "con la evidencia de haberlo experimentado en 4 años que ha sido alcalde... certifico ser cierto el que en esta villa no hay ningún natural que pueda intitularse indio, porque los que hay en esta jurisdicción están recogidos y avecindados en la nueva población de Jiguani"

El alcalde Joseph Ramírez ratificó lo anterior y agregó: "Los que hay de gente pobre son mestizos, mulatos y negros, y muchos de ellos nacidos en otras partes... los descendientes de dichos indios en virtud de R. P. se hallan retirados en Jiguani... y aun cuando hubiera en esta villa algunos naturales se debieran retirar a dicho pueblo, como les está mandado" [Leví Marrero: Cuba. Economía y sociedad, Vol. 6, p. 12].

\section{Datos de filiación}

Gerardo Licea Bello es Licenciado en Historia en la Universidad de Holguín, Cuba, 2012, donde en estos momentos también desarrolla estudios de maestría.

Ha participado en eventos científicos de carácter nacional e internacional celebrados en Cuba. Obtuvo el Premio de la Ciudad de Holguín 2017 en Historia, con la monografía "Cabildo y oligarquía en Holguín (1752-1833)”, la cual será publicada en forma de libro por Ediciones Holguín en el 2018. Sus intereses de investigación se concentran en temas como Historia social de Cuba colonial (siglos XVI-XIX); historia de las instituciones coloniales españolas así como la historia regional de las poblaciones cubanas de Bayamo, Holguín y Jiguaní. 